American Journal of Pharmaceutical Education 2018; 82 (6) Article 6302.

\title{
RESEARCH
}

\section{Pharmacy Competencies for Interprofessional Integrative Health Care Education}

\author{
Jeannie K. Lee, PharmD, Anne L. Hume, PharmD, Robert Willis, PharmD, Heather Boon, PhD, BScPhm, \\ Patricia Lebensohn, MD, Audrey Brooks, PhD, Ben Kligler, MD, MPH \\ University of Arizona College of Pharmacy, Tucson, Arizona
}

Submitted January 25, 2017; accepted July 3, 2017; published August 2018.

\begin{abstract}
Objective. To address the gap in evidence-based knowledge among pharmacy students and practicing pharmacists regarding complementary and integrative health approaches due to insufficient education and a lack of standardized training.

Methods. The National Center for Integrative Primary Healthcare (NCIPH) developed 22 pharmacy competencies linked to a set of 10 interprofessional "metacompetencies" in integrative health care.

Results. The NCIPH pharmacy competencies are well-aligned with the current educational standards and Center for the Advancement of Pharmacy Education (CAPE) outcomes for pharmacy programs. Therefore, the NCIPH competencies may provide a foundation for the incorporation of interprofessional integrative health care education into pharmacy curricula.

Conclusion. The NCIPH pharmacy competencies in integrative health care, linked to the interprofessional "metacompetencies," are aligned with educational standards and outcomes, and may serve as a basis for pharmacy curriculum.
\end{abstract}

Keywords: integrative health care, pharmacy competencies, pharmacy education

\section{INTRODUCTION}

More Americans now use complementary and integrative health care than ever before. According to the 2012 National Health Interview Survey (NHIS) conducted by the National Center for Complementary and Integrative Health (NCCIH) and Center for Disease Control and Prevention (CDC), the use of many complementary and integrative approaches for health significantly increased between 2007 and 2012 in the United States. ${ }^{1}$ The key findings from the NHIS revealed widespread use of natural products (dietary supplements outside of vitamins and minerals) along with mind and body practices (eg, yoga, meditation, chiropractic services). ${ }^{2}$ An estimated 59 million Americans spend $\$ 30.2$ billion annually outof-pocket on natural products and mind-body practices. ${ }^{2}$ The out-of-pocket spending ranked highest for complementary practitioner visits ( $\$ 143.7$ billion, nearly 30\% of what was spent on conventional physician services), followed by natural products ( $\$ 12.8$ billion, $24 \%$ of the out-of-pocket amount spent on prescription drugs) and self-care approaches, such as homeopathic medicine

Corresponding Author: Jeannie K. Lee, University of Arizona College of Pharmacy, 1295 N. Martin Ave., PO Box 210202, Tucson, AZ 85721-0202. Tel: 520-626-9419. Fax: 520-626-7355. E-mail: jlee@pharmacy.arizona.edu and self-help materials ( $\$ 2.7$ billion). ${ }^{3}$ As family income increased, out-of-pocket spending on complementary approaches also increased. ${ }^{3}$

When describing non-conventional approaches to health, the terms "alternative," "complementary," and "integrative" have been used interchangeably. However, these nomenclatures have varying definitions. While "alternative" approaches refer to nonconventional strategies used in place of conventional interventions, "complementary" approaches refer to nonconventional strategies used together with conventional interventions. ${ }^{2}$ Complementary approaches are much more commonly used than alternative approaches in the U.S. In turn, the term "integrative," which means bringing together conventional and complementary approaches in a coordinated way, is now gaining use. $^{2}$ The Office of Alternative Medicine (OAM), established within the National Institute of Health (NIH)'s Office of the Director in 1992, was elevated and established as a National Center for Complementary and Alternative Medicine (NCCAM) in 1998 to evaluate complementary and alternative health interventions. ${ }^{4}$ Recognizing that true alternative practices are rare and to promote the coordinated bridging of complementary practices to conventional care, the center changed its name to the National Center for Complementary and Integrative Health (NCCIH) in 2014. ${ }^{4}$ In general, "complementary approaches" should 


\section{American Journal of Pharmaceutical Education 2018; 82 (6) Article 6302.}

be used when referring to nonconventional practices and products for health, and "integrative health" used when referring to incorporation of complementary approaches together with conventional care. ${ }^{2}$ Thus, pharmacy education should focus on complementary and integrative health.

Broadly, complementary approaches for health can be divided into two groups: natural products and mind and body practices. $^{2}$ Table 1 illustrates these two groups and components within each broad approach, along with other whole system practices that are outside the two groups. ${ }^{2,5}$ Whole system practices involve complete systems of theory and practice that maximize patients' ability to achieve physical and mental health. ${ }^{5}$ Since 2002, NHIS consistently showed that the most commonly used complementary health approach has been natural products. ${ }^{6}$ The top 10 most commonly used complementary approaches by US adults in 2012 were: natural products, deep breathing, yoga, tai chi, or qi gong, chiropractic or osteopathic manipulation, meditation, massage, special diets, homeopathy, progressive relaxation, and guided imagery. ${ }^{2}$ Among the natural products, fish oil was most commonly used by adults. ${ }^{6}$ The use of fish oil, probiotics and melatonin increased from 2007 to $2012 .{ }^{6}$ The natural products were most often used for wellness, but also to reduce stress, improve sleep, or feel better emotionally. ${ }^{6}$ Similar reasons were reported by people using mind and body practices. ${ }^{6}$ The most recent market research report on vitamin and supplement manufacturing in the US presented the supplement market as an $\$ 18$ billion industry with a yearly growth rate of approximately $5 \% .^{7}$

Compared with medicine and nursing, in which the field of integrative health has matured over the past 20 years, pharmacy education lags in terms of having established competencies and standards. More than $40 \%$ of medical schools in the U.S. are members of the Academic Consortium for Integrative Medicine and Health. ${ }^{8}$ The Society of
Teachers of Family Medicine approved 19 integrative medicine competencies for Family Medicine Residency programs in 2010. ${ }^{8}$ A national board certification in integrative medicine that requires fellowship training was established in 2013. ${ }^{9}$ In nursing, the American Nurses Association and American Holistic Nurses Association have established the scope and standards of holistic nursing. ${ }^{10-12}$

Although competencies and content criteria for integrative health care have not been identified by the Accreditation Council on Pharmacy Education (ACPE), the National Association of Boards of Pharmacy (NABP) has established guidelines on natural products competency in the North American Pharmacist Licensure Examination (NAPLEX). ${ }^{13}$ A 2003 study found that teaching in complementary and alternative medicine was offered often as elective courses in many pharmacy programs $(79 \%$ in state and $86 \%$ in private institutions). ${ }^{14}$ Among pharmacy students and faculty, support is strong for incorporating integrative health content into the required curriculum, recognizing the importance of pharmacist competency on the topic given its popularity among consumers. ${ }^{13,15,16}$ Several examples of course implementation in pharmacy curriculum and evaluation of students exist, with outcomes showing positive changes in students' knowledge of, attitudes and perceptions toward, and likelihood of recommending evidence-based complementary medicine or natural products. ${ }^{17-20}$ In addition, students wanted more training on complementary medicine and earlier rather than later in the curriculum. ${ }^{15,17}$

Community pharmacies have been identified by consumers as a common place to obtain vitamin supplements and natural products, and consumers expect pharmacists to be knowledgeable about these agents to offer advice. ${ }^{21,22}$ However, studies that targeted pharmacists have revealed feelings of inadequate knowledge and skills possessed on

Table 1. Examples of Complementary Health Approaches ${ }^{5}$

\begin{tabular}{llcc}
\hline Natural Products & & Mind and Body Practices & Whole Systems \\
\hline Vitamins and minerals & Yoga & Tai chi & Traditional healer \\
(eg, multivitamin, thiamine, & Chiropractic and osteopathic & Qi gong & Ayurvedic medicine \\
vitamin C, vitamin B6, & manipulation & Healing touch & Traditional Chinese \\
folic acid) & Meditation & Hypnotherapy & medicine \\
Dietary supplements & Massage therapy & Movement therapies & Homeopathy \\
(eg, fish oil, calcium, & Acupuncture & (eg, Feldenkrais method, & Naturopathy \\
coenzyme Q-10, cranberry) & Relaxation techniques & Alexander technique, Pilates, \\
Herbs (eg, botanicals, & (eg, breathing exercises, & Rolfing Structural Integration, \\
spices, essential oils, teas) & guided imagery, progressive & Trager psychophysical integration) \\
Probiotics & muscle relaxation) & & \\
(eg, lactobacillus acidophilus, & & & \\
saccharomyces boulardii) & & & \\
\hline
\end{tabular}




\section{American Journal of Pharmaceutical Education 2018; 82 (6) Article 6302.}

Table 2. National Center on Integrative Primary Healthcare (NCIPH) Interprofessional Competencies and Pharmacy Competencies

Interprofessional Competencies $^{33}$

1. Practice patient-centered and relationship-based care.

2. Obtain a comprehensive health history which includes mind-body-spirit, nutrition, and the use of conventional, complementary and integrative therapies and disciplines.

3. Collaborate with individuals and families to develop a personalized plan of care to promote health and well-being which incorporates integrative approaches including lifestyle counseling and the use of mind-body strategies.

4. Demonstrate skills in utilizing the evidence as it pertains to integrative healthcare.

5. Demonstrate knowledge about the major conventional, complementary and integrative health professions.

6. Facilitate behavior change in individuals, families and communities.

7. Work effectively as a member of an interprofessional team.
Pharmacy Competencies

1. Provide care that is person-centered and relationship-based

2. Demonstrate respect and understanding for patients' interpretations of health, disease, and illness that are based upon their cultural beliefs and practices

3. Employ motivational interviewing and effective educational strategies that encourage patient engagement in symptom and disease self-management and strategies that improve whole person wellbeing

4. Demonstrate patient-centered history taking that includes physical, nutritional, social, economic, emotional, mental, environmental, and spiritual aspects of health and wellbeing that includes inquiry of conventional and complementary approaches

5. Perform integrative health-related patient assessment that includes preventive, pharmaceutical, nutritional, behavioral, social, economic, cultural, environmental and spiritually-relevant determinants

6. Collaborate with patients and care partners in conducting a health screening and management plan for disease prevention and treatment using conventional, complementary and integrative therapies when indicated

7. Demonstrate the required knowledge and skills to incorporate integrative health-based self-care and self-management principles into practice settings

8. Educate patients and communities in health promotion and disease prevention

9. Evaluate the strengths and limitations of evidence-based conventional, complementary and integrative healthcare approaches and translation into patient care

10. Use evidence-based conventional, complementary and integrative healthcare resources at the point of care for prevention and treatment

11. Demonstrate a basic knowledge of the standards, training, credentialing, expertise, knowledge and skills of conventional, complementary and integrative health professionals to promote optimal interprofessional collaboration

12. Describe common integrative therapies, including their history, proposed mechanisms, dose/potency and duration, safety and efficacy profiles, contraindications, and patterns of use

13. Facilitate health behavior changes in patients, care partners and communities using an integrative health approach

14. Implement person-centered shared decision making that potentially includes integrative healthcare

15. Engage diverse health professionals who complement pharmacists' expertise to develop strategies to meet specific patient, care partners and community health needs

16. Demonstrate respect for diverse conventional, complementary and integrative professionals who share in the care of patients

17. Identify differences among diverse health systems and models used by conventional, complementary and integrative professionals 


\section{American Journal of Pharmaceutical Education 2018; 82 (6) Article 6302.}

Table 2. (Continued)

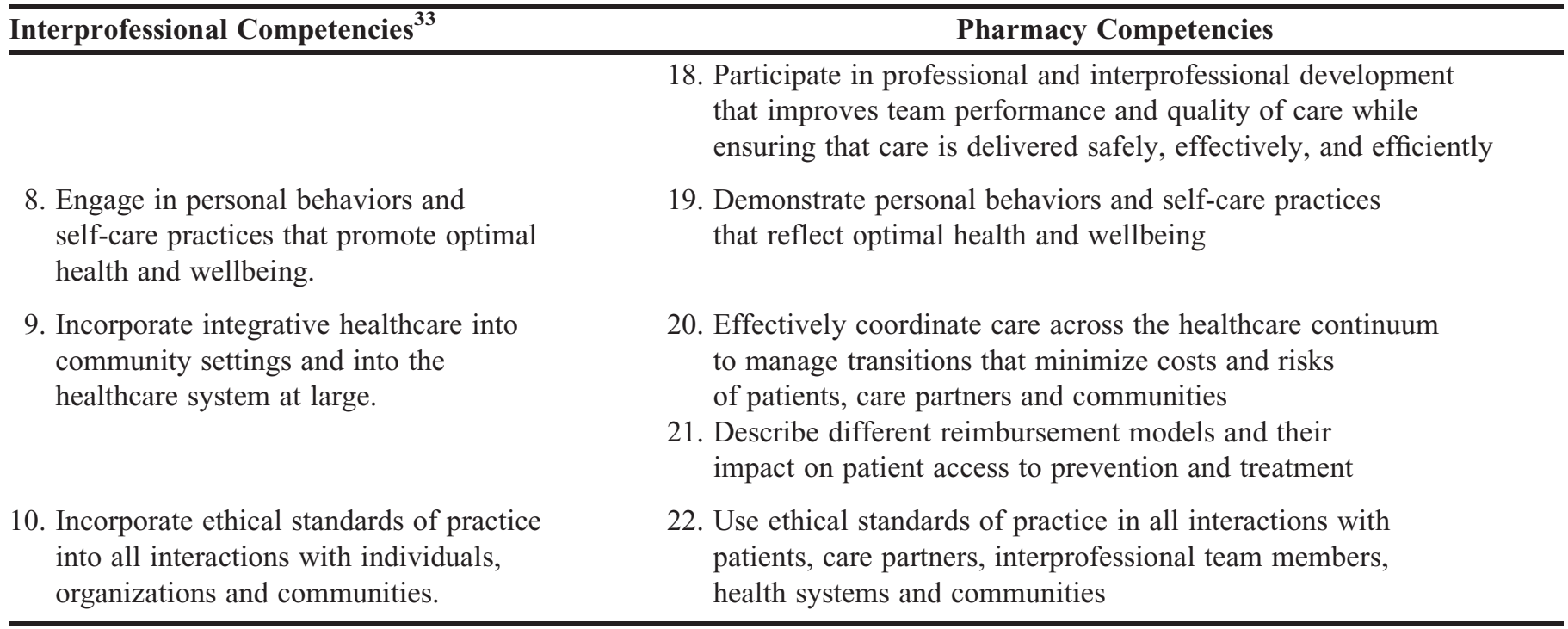

this topic, with an overwhelming majority supporting increased emphasis within pharmacy curricula. ${ }^{22,23}$ With the rise in complementary and integrative health approaches used for multiple diseases such as pain, diabetes, chronic kidney disease, depression and cancer, increased reports of toxicities and harm from use of certain natural products have occurred. $^{24-32}$ Therefore, a significant need exists for greater education for pharmacy students and practicing pharmacists on complementary and integrative health approaches including natural medicines. Given the shift in health care practice toward team-based care, an appropriate starting point for pharmacy initiatives is the establishment of educational competencies for integrative health care that aligns with existing interprofessional competencies in integrative health care. ${ }^{33,34}$

\section{METHODS}

The National Center for Integrative Primary Healthcare (NCIPH) was established to develop a core set of interprofessional competencies and curriculum in integrative health care, coordinate the development of subcompetencies for diverse professions, and to advance the incorporation of the competencies in education and training of a wide range of health professionals. Funded by the Health Resources and Services Administration (HRSA), the NCIPH has worked for three years to develop and disseminate these core interprofessional competencies. The NCIPH's Interprofessional Leadership Team reviewed the competencies from family medicine, preventive medicine, nursing, medical student education, integrative medicine fellowship, the Interprofessional Collaborative Practice, and diverse professional standards, including the licensed integrative health disciplines, to develop, refine and adopt 10 "meta-competencies" previously published. ${ }^{10-12,33-41}$ Using the 10 meta-competencies as a foundation, an online Foundations in Interprofessional Integrative Health course ( 35 hours) was created and pilot-tested across a spectrum of interprofessional primary care practitioners including pharmacists. ${ }^{33,34}$

Following the adoption and publication of the metacompetencies by the NCIPH, individual leadership team members from different professions drafted their professionspecific sub-competencies linked to each interprofessional meta-competency. The pharmacy competencies draft was widely circulated for comments among pharmacy leaders in integrative health, authors and teachers of integrative health topics, and national organization representatives. The pharmacist member of the NCIPH leadership team revised the pharmacy competencies according to the comments received. The competency set was then finalized by the NCIPH Interprofessional Leadership Team. To increase the relevance to pharmacy education, the adapted NCIPH pharmacy competencies were mapped to educational outcomes outlined by the Center for the Advancement of Pharmacy Education (CAPE) and to Bloom's Taxonomy. ${ }^{42,43}$

\section{RESULTS}

A total of 22 sub-competencies for pharmacy, linked to the $10 \mathrm{NCIPH}$ meta-competencies, were developed as shown in Table 2 and disseminated through emails and the NCIPH website. Most meta-competency domains included two to three pharmacy competencies, except domains 7,8 and 10. The meta-competency 7 on "work effectively as a member of an interprofessional team" was correlated with four sub-competencies for pharmacy 


\section{American Journal of Pharmaceutical Education 2018; 82 (6) Article 6302.}

Table 3. National Center on Integrative Primary Healthcare (NCIPH) Pharmacy Competencies Mapped to the CAPE Outcomes and Bloom's Taxonomy

\begin{tabular}{|c|c|c|}
\hline Pharmacy Competencies & $\begin{array}{l}\text { CAPE Educational } \\
\text { Outcomes Domains }^{42}\end{array}$ & 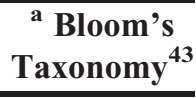 \\
\hline 1. Provide care that is person-centered and relationship-based. & 2.1 & Ap \\
\hline $\begin{array}{l}\text { 2. Demonstrate respect and understanding for patients' interpretations of health, } \\
\text { disease, and illness that are based upon their cultural beliefs and practices. }\end{array}$ & $1.1,2.1,3.5$ & C, Ap \\
\hline $\begin{array}{l}\text { 3. Employ motivational interviewing and effective educational strategies that } \\
\text { encourage patient engagement in symptom and disease self-management } \\
\text { and strategies that improve whole person well-being. }\end{array}$ & $1.1,2.1,3.2,3.6$ & C, Ap \\
\hline $\begin{array}{l}\text { 4. Demonstrate patient-centered history taking that includes physical, } \\
\text { nutritional, social, economic, emotional, mental, environmental, and } \\
\text { spiritual aspects of health and well-being that includes inquiry of } \\
\text { conventional and complementary approaches. }\end{array}$ & $2.2,3.5,3.6$ & Ap \\
\hline $\begin{array}{l}\text { 5. Perform integrative health-related patient assessment that includes } \\
\text { preventive, pharmaceutical, nutritional, behavioral, social, economic, } \\
\text { cultural, environmental and spiritually relevant determinants. }\end{array}$ & 3.5 & Ap \\
\hline $\begin{array}{l}\text { 6. Collaborate with patients and care partners in conducting a health screening } \\
\text { and management plan for disease prevention and treatment using } \\
\text { conventional, complementary and integrative therapies when indicated. }\end{array}$ & $2.1,2.3$ & Ap \\
\hline $\begin{array}{l}\text { 7. Demonstrate the required knowledge and skills to incorporate integrative } \\
\text { health-based self-care and self-management principles into practice settings. }\end{array}$ & 1.1 & $\mathrm{~K}, \mathrm{C}$ \\
\hline $\begin{array}{l}\text { 8. Educate patients and communities in health promotion and disease } \\
\text { prevention }\end{array}$ & $3.2,2.3,2.4$ & Ap \\
\hline $\begin{array}{l}\text { 9. Evaluate the strengths and limitations of evidence-based conventional, } \\
\text { complementary and integrative health care approaches and translation into } \\
\text { patient care. }\end{array}$ & $2.1,3.1$ & An, E \\
\hline $\begin{array}{l}\text { 10. Use evidence-based conventional, complementary and integrative health } \\
\text { care resources at the point of care for prevention and treatment. }\end{array}$ & $2.1,2.3$ & Ap, $\mathrm{S}$ \\
\hline $\begin{array}{l}\text { 11. Demonstrate a basic knowledge of the standards, training, credentialing, } \\
\text { expertise, knowledge and skills of conventional, complementary and } \\
\text { integrative health professionals to promote optimal interprofessional } \\
\text { collaboration. }\end{array}$ & $1.1,3.4$ & $\mathrm{~K}$ \\
\hline $\begin{array}{l}\text { 12. Describe common integrative therapies, including their history, proposed } \\
\text { mechanisms, dose/potency and duration, safety and efficacy profiles, } \\
\text { contraindications, and patterns of use. }\end{array}$ & $1.1,2.2$ & $\mathrm{~K}, \mathrm{C}$ \\
\hline $\begin{array}{l}\text { 13. Facilitate health behavior changes in patients, care partners and } \\
\text { communities using an integrative health approach. }\end{array}$ & $2.1,2.3,2.4$ & Ap \\
\hline $\begin{array}{l}\text { 14. Implement person-centered shared decision making that potentially includes } \\
\text { integrative health care. }\end{array}$ & 2.1 & Ap, S, E \\
\hline $\begin{array}{l}\text { 15. Engage diverse health professionals who complement pharmacists' } \\
\text { expertise to develop strategies to meet specific patient, care partners and } \\
\text { community health needs. }\end{array}$ & $3.4,4.2$ & An, $\mathrm{S}$ \\
\hline $\begin{array}{l}\text { 16. Demonstrate respect for diverse conventional, complementary and } \\
\text { integrative professionals who share in the care of patients. }\end{array}$ & 4.1, 4.4 & Ap \\
\hline $\begin{array}{l}\text { 17. Identify differences among diverse health systems and models used by } \\
\text { conventional, complementary and integrative professionals. }\end{array}$ & $1.1,3.4$ & An \\
\hline $\begin{array}{l}\text { 18. Participate in professional and interprofessional development that improves } \\
\text { team performance and quality of care while ensuring that care is delivered } \\
\text { safely, effectively, and efficiently. }\end{array}$ & $3.4,4.2$ & $\mathrm{~S}, \mathrm{E}$ \\
\hline $\begin{array}{l}\text { 19. Demonstrate personal behaviors and self-care practices that reflect optimal } \\
\text { health and well-being. }\end{array}$ & $2.3,4.1$ & Ap \\
\hline
\end{tabular}




\section{American Journal of Pharmaceutical Education 2018; 82 (6) Article 6302.}

Table 3. (Continued)

\begin{tabular}{|c|c|c|}
\hline Pharmacy Competencies & $\begin{array}{l}\text { CAPE Educational } \\
\text { Outcomes Domains }{ }^{42}\end{array}$ & $\begin{array}{c}\text { a Bloom's } \\
\text { Taxonomy }\end{array}$ \\
\hline $\begin{array}{l}\text { 20. Effectively coordinate care across the health care continuum to manage } \\
\text { transitions that minimize costs and risks of patients, care partners and } \\
\text { communities. }\end{array}$ & $2.2,4.3$ & Ap, E \\
\hline $\begin{array}{l}\text { 21. Describe different reimbursement models and their impact on patient access } \\
\text { to prevention and treatment. }\end{array}$ & 2.2 & $\mathrm{C}, \mathrm{An}$ \\
\hline
\end{tabular}

on engaging diverse health professionals, demonstrating respect, identifying differences among health systems and models used, and participating in professional and interprofessional development to improve team performance. The meta-competencies 8 and 10 on "engage in personal behaviors and self-care practices that promote optimal health and well-being" and "incorporate ethical standards of practice into all interactions with individuals, organizations and communities," respectively, were coupled with a single pharmacy competency each.

Table 3 illustrates the alignment of the NCIPH pharmacy competencies with associated 2013 CAPE outcomes domains and Bloom's Taxonomy categories. ${ }^{42,43}$ As expected, the integrative health pharmacy competencies, with an emphasis in interprofessional care, were well correlated with the CAPE outcomes, having components from all four domains represented. ${ }^{42}$ The NCIPH pharmacy competencies also mapped readily to Bloom's Taxonomy with "application" category most often represented, though all six categories were noted. ${ }^{43}$

\section{DISCUSSION}

The pharmacy competencies in integrative health care, associated with the NCIPH interprofessional metacompetencies, are well aligned with the CAPE outcomes and Bloom's Taxonomy, making them ideal for curricular implementation in schools and colleges of pharmacy. The findings from available educational research indicate the need for greater emphasis on complementary and integrative health within pharmacy curricula to equip pharmacists with knowledge and skills needed to provide evidencebased guidance to meet public demand. ${ }^{21-23}$ At the same time, a strong interest among pharmacy students and faculty has been recognized. ${ }^{13-16}$ The NCIPH pharmacy competencies, established through an extensive vetting process among pharmacists and academic experts, may serve as a starting point for educational and training initiatives in complementary medicine and integrative health care.
The inclusion of complementary and integrative health in pharmacy curricula is supported by the ACPE standards and guidelines, particularly in standards 2, 3 and $11 .{ }^{44}$ Standard 2 is on Essentials for Practice and Care with key elements of patient-centered care and health and wellness that point to the importance of establishing competencies in complementary and integrative health. Standard 3 on Approach to Practice and Care includes key elements of education, patient advocacy, interprofessional collaboration and cultural sensitivity, for which complementary and integrative health knowledge may be crucial. Standard 11 on Interprofessional Education with key elements of interprofessional team education and interprofessional team practice also injects the need for competent knowledge and skills in complementary and integrative health for pharmacists serving as members of interprofessional teams. ${ }^{44}$ Thus, it would be logical to incorporate integrative health care content within didactic teaching focused on the evidence base. Likewise, evidenced-based knowledge on complementary and integrative health would be valuable for student pharmacists to further acquire and apply during their introductory and advanced pharmacy practice experiences. Additionally, acquiring knowledge about complementary and integrative health approaches may be empowering to students, both for patient care and self-care. Since burnout is a concern among pharmacy students working through rigorous curriculum and extracurricular responsibilities, seeking ways for self-care to obtain and maintain resilience is important. ${ }^{45,46}$ For selfcare, student pharmacists may be able to use complementary approaches to reduce stress and integrative health if suffering from health conditions.

The online Foundations in Interprofessional Integrative Health course based on the NCIPH meta-competencies has been pilot-tested among numerous interprofessional practitioners and students, including pharmacy programs. Based on the feedback from the pilot study, the course 


\section{American Journal of Pharmaceutical Education 2018; 82 (6) Article 6302.}

was revised and is available at https://nciph.org/ curriculum.html. In the Foundations course, the pharmacy competencies were used to guide the development of an interactive case study in patient assessment, where a pharmacist conducts an interview of a patient with chronic diseases using polypharmacy including natural products. In addition, pharmacist input was provided for all of the cases used in the course as part of interprofessional collaboration. Next steps are to widely disseminate and promote adoption of the NCIPH meta-competencies among primary care professions and disciplines. At the same time, utilization of pharmacy competencies in creation and implementation of complementary and integrative health educational efforts across pharmacy programs will be advocated.

\section{CONCLUSION}

Consumer and patient interest in complementary and integrative approaches to health and health care has continued to grow. The existing level of education of pharmacy students and practicing pharmacists regarding these approaches may not be sufficient to contribute to high quality patient-centered care, especially compared with other health professions. The adoption of pharmacy-based competencies in integrative health care that are well aligned with the CAPE outcomes and consistent with interprofessional competencies is a first important step.

\section{ACKNOWLEDGMENTS}

This project is supported by the Health Resources and Services Administration (HRSA) of the U.S. Department of Health and Human Services (HHS) under grant number UE1HP27710, Integrative Medicine: Empowering Communities through Interprofessional Primary Care Teams. This information or content and conclusions are those of the author and should not be construed as the official position or policy of, nor should any endorsements be inferred by HRSA, HHS or the U.S. Government.

\section{REFERENCES}

1. Briggs J. New data reveal Americans' use of complementary health approaches. NCCIH Web site. https://nccih.nih.gov/about/ offices/od/NHIS2012. Updated 2015. Accessed December 1, 2016. 2. Centers for Disease Control and Prevention, National Center for Health Statistics. National health statistics report. https://www.cdc. gov/nchs/products/nhsr.htm. Accessed December 1, 2016. 3. National Center for Complementary and Integrative Health. Americans spend $\$ 30$ billion a year out-of-pocket on complementary health approaches. https://nccih.nih.gov/research/results/spotlight/ americans-spend-billions. Updated 2016. Accessed December 1, 2016. 4. National Center for Complementary and Integrative Health. NIH complementary and integrative health agency gets new name. https://www.nih.gov/news-events/news-releases/nih-complementaryintegrative-health-agency-gets-new-name. Updated 2015. Accessed December 19, 2016.

5. Ritenbaugh C, Verhoef M, Fleishman S, Boon H, Leis A. Whole systems research: a discipline for studying complementary and alternative medicine. Altern Ther Health Med. 2003;9(4):32-36. 6. National Center for Complementary and Integrative Health. National health interview survey. What complementary and integrative approaches do Americans use? https://nccih.nih.gov/ research/statistics/NHIS/2012/key-findings. Updated 2015. Accessed December 1, 2016.

7. Bhargava H. Do you know what supplements your patients are using? Medscape; 2016.

8. Locke AB, Gordon A, Guerrera MP, Gardiner P, Lebensohn P. Recommended integrative medicine competencies for family medicine residents. Explore (NY). 2013;9(5):308-313.

9. Maizes V, Horwitz R, Lebensohn P, McClafferty H, Dalen J, Weil A. The evolution of integrative medical education: the influence of the University of Arizona Center for Integrative Medicine. $J$ Integrat Med. 2015;13(6):356-362.

10. American Holistic Nurses Association and American Nurses Association. Holistic Nursing: Scope and Standards of Practice. 2nd ed. Silver Spring, MD: American Nurses Association; 2013. http://www.r2library.com/resource/title/9781558104785.

11. American Holistic Nurses Credentialing Corporation. Core essentials for the practice of advanced holistic nursing AHN-BC and APHN-BC. 2012.

12. American Holistic Nurses Credentialing Corporation.

Professional nurse coach role: core essentials. 2012.

13. Kostka-Rokosz MD, Dvorkin-Camiel L, Asabigi AL. Student and faculty perspective toward the role and value of integration of natural product information into the pharmacy curriculum. $J$ Diet Suppl. 2011;8(1):12-18.

14. Shields KM, McQueen CE, Bryant PJ. Natural product education in schools of pharmacy in the united states. Am J Pharm Educ. 2003;67(1):Article 10.

15. Harris IM, Kingston RL, Rodriguez R, Choudary V. Attitudes towards complementary and alternative medicine among pharmacy faculty and students. Am J Pharm Educ. 2006;70(6):Article 129. 16. Johnson T, Boon H. Where does homeopathy fit in pharmacy practice? Am J Pharm Educ. 2007;71(1):Article 7.

17. Tiralongo E, Wallis M. Integrating complementary and alternative medicine education into the pharmacy curriculum. Am J Pharm Educ. 2008;72(4):Article 74.

18. Steenfeldt L, Hughes J. An evidence-based course in complementary medicines. Am J Pharm Educ. 2012;76(10):Article 200.

19. Evans E, Evans J. Changes in pharmacy students' attitudes and perceptions toward complementary and alternative medicine after completion of a required course. Am J Pharm Educ. 2006;70(5): Article 105.

20. Maree Simpson, Heather Cavanagh, George John, et al. Complementing a rural pharmacy course with CAM: reflections from a decade of experience. Pharmacy. 2014;2(1):88-97.

21. Koh HL, Teo H, Ng HL. Pharmacists' patterns of use, knowledge, and attitudes toward complementary and alternative medicine. J Altern Complement Med. 2003;9(1):51-63.

22. Braun LA, Tiralongo E, Wilkinson JM, et al. Perceptions, use and attitudes of pharmacy customers on complementary medicines and pharmacy practice. BMC Complement Altern Med. 2010;10(1):38. 


\section{American Journal of Pharmaceutical Education 2018; 82 (6) Article 6302.}

23. Kwan D, Boon HS, Hirschkorn K, et al. Exploring consumer and pharmacist views on the professional role of the pharmacist with respect to natural health products: a study of focus groups. $B M C$ Complement Altern Med. 2008;8(1):40.

24. Murthy V, Sibbritt DW, Adams J. An integrative review of complementary and alternative medicine use for back pain: a focus on prevalence, reasons for use, influential factors, self-perceived effectiveness, and communication. Spine J. 2015;15(8):1870-1883. 25. Abbasi J. As opioid epidemic rages, complementary health approaches to pain gain traction. JAMA. 2016;316(22):2343-2344. 26. Wolever RQ, Dreusicke MH. Integrative health coaching: A behavior skills approach that improves $\mathrm{HbAlc}$ and pharmacy claimsderived medication adherence. BMJ Open Diabetes Res Care. 2016; 4(1):e000201.

27. Arjuna Rao AS, Phaneendra D, Pavani ChD, et al. Usage of complementary and alternative medicine among patients with chronic kidney disease on maintenance hemodialysis. J Pharmacy Bioallied Sci. 2016;8(1):52-57.

28. Solomon D, Adams J. The use of complementary and alternative medicine in adults with depressive disorders. A critical integrative review. J Affect Disord. 2015;179:101-113.

29. Farooqui M, Hassali MA, Shatar AK, et al. Use of complementary and alternative medicines among Malaysian cancer patients: a descriptive study. J Tradit Complement Med. 2015;6(4):321-326. 30. Xiang Lei, Jing Chen, Jingtian Ren, et al. Liver damage associated with polygonum multiflorum thunb: a systematic review of case reports and case series. Evidence-Based Complement Alternat Med. 2015:Article 459749.

31. Jatau AI, Aung MM, Kamauzaman TH, Chedi BA, Sha'aban A, Rahman AF. Use and toxicity of complementary and alternative medicines among patients visiting emergency department: systematic review. J Intercultural Ethnopharmacol. 2016;5(2):191-197.

32. Consumer Reports. 15 ingredients to always avoid. Consumer Reports. 2016;81(9):24.

33. Kligler B, Brooks AJ, Maizes V, et al. Interprofessional competencies in integrative primary healthcare. Glob Adv Health Med. 2015;4(5):33-39.

34. National Center for Integrative Primary Healthcare. https:// nciph.org/. Accessed December 1, 2016.

35. Kligler B, Gordon A, Stuart M, Sierpina V. Suggested curriculum guidelines on complementary and alternative medicine: recommendations of the society of teachers of family medicine group on alternative medicine. Fam Med. 2000;32(1):30-33.

36. Jani AA, Trask J, Ali A. Integrative Medicine in Preventive Medicine Education: Competency and Curriculum Development for Preventive Medicine and Other Specialty Residency Programs. Am J Prev Med. 2015;49(5 Suppl 3):S222-9. doi: 10.1016/j.amepre.2015.08.019.

37. Kligler B, Maizes V, Schachter S, et al. Core competencies in integrative medicine for medical school curricula: a proposal. Acad Med. 2004;79(6):521-531.

38. Ring M, Brodsky M, Low Dog T, et al. Developing and implementing core competencies for integrative medicine fellowships. Acad Med. 2014;89(3):421-428.

39. Interprofessional Education Collaborative. Core competencies for interprofessional collaborative practice: 2016 update. https:// www.tamhsc.edu/ipe/research/ipec-2016-core-competencies.pdf. 40. Brett J, Brimhall J, Healey D, Pfeifer J, Prenguber M. Competencies for public health and interprofessional education in accreditation standards of complementary and alternative medicine disciplines. Explore (NY). 2013;9(5):314-320.

41. Goldblatt E, Wiles M, Schwartz J, Weeks J. Competencies for optimal practice in integrated environments: examining attributes of a consensus interprofessional practice document from the licensed integrative health disciplines. Explore (NY). 2013;9(5):285-291. 42. Medina MS, Plaza CM, Stowe CD, et al. Center for the Advancement of Pharmacy Education 2013 educational outcomes. Am J Pharm Educ. 2013;77(8):Article 162.

43. Bloom BS. Taxonomy of Educational Objectives: The Classification of Educational Goals. New York, NY: DMcKay Co; 1974.

44. Accreditation Council for Pharmacy Education. Accreditation standards and key elements for the professional program in pharmacy leading to the doctor of pharmacy degree. Standards 2016. https:// www.acpe-accredit.org/pdf/Standards2016FINAL.pdf. 45. Varkey AC. Promoting resiliency: recognizing and preventing burnout. American Pharmacists Association. https://www. pharmacist.com/promoting-resiliency-recognizing-and-preventingburnout. Updated 2014. Accessed January 25, 2017.

46. Ried LD, Motycka C, Mobley C, Meldrum M. Comparing selfreported burnout of pharmacy students on the founding campus with those at distance campuses. Am J Pharm Educ. 2006;70(5):Article 114 